\title{
Analytic Method on Characteristic Parameters of Bacteria in Water by Multiwavelength Transmission Spectroscopy
}

\author{
Yuxia Hu, ${ }^{1,2,3}$ Nanjing Zhao, ${ }^{1,3}$ Tingting Gan, ${ }^{1,3}$ Jingbo Duan, ${ }^{1,3}$ Hui Juan Yu, ${ }^{1,2,3}$ \\ Deshuo Meng, ${ }^{1,3}$ Jianguo Liu, ${ }^{1,3}$ and Wenqing Liu ${ }^{1,3}$ \\ ${ }^{1}$ Key Laboratory of Environmental Optics and Technology, Anhui Institute of Optics and Fine Mechanics, \\ Chinese Academy of Sciences, Hefei 230031, China \\ ${ }^{2}$ University of Science and Technology of China, Hefei 230026, China \\ ${ }^{3}$ Key Laboratory of Optical Monitoring Technology for Environment, Anhui Province, Hefei 230031, China
}

Correspondence should be addressed to Nanjing Zhao; njzhao@aiofm.ac.cn

Received 19 April 2017; Accepted 31 October 2017; Published 27 December 2017

Academic Editor: Tino Hofmann

Copyright ( 2017 Yuxia Hu et al. This is an open access article distributed under the Creative Commons Attribution License, which permits unrestricted use, distribution, and reproduction in any medium, provided the original work is properly cited.

An analytic method together with the Mie scattering theory and Beer-Lambert law is proposed for the characteristic parameter determination of bacterial cells (Escherichia coli 10389) from multiwavelength transmission spectroscopy measurements. We calculate the structural parameters of $E$. coli cells, and compared with the microscopy, the relative error of cell volume is $7.90 \%$, the cell number is compared with those obtained by plate counting, the relative error is $1.02 \%$, and the nucleic content and protein content of single $E$. coli cells are consistent with the data reported elsewhere. The proposed method can obtain characteristic parameters of bacteria as an excellent candidate for the rapid detection and identification of bacteria in the water.

\section{Introduction}

Different kinds of bacteria have different pollution degrees of water body; consequently, determining the characteristics and concentration of bacteria in the water plays an important role in guaranteeing the security of drinking water. E. coli is a prokaryotic organism known to cause diarrhea in humans and other animals, which is an important indicator bacterium in environmental water quality monitoring and food security [1-4].

At present, the existing detection methods of the concentration and physical structure and compositional characteristics of bacteria, such as isolation and culture [5-7], immunology $[8,9]$, nucleic acid hybridization [10], polymerase chain reaction $[11,12]$, and protein-chip technology [13], provide precise results, but there are still some limitations existing such as complex operation and long analysis time. In order to realize rapid detection of bacteria, some spectroscopy techniques, such as fluorescence [14-16], infrared [17-19], and Raman [20-23], have also been used for the determination of characteristic parameters of bacteria. The disadvantages associated with those spectroscopy techniques include the high performance requirements for instrumentation and the inability to provide detailed information of the structural and compositional characteristics of the bacteria cells.

Multiwavelength transmission spectroscopy is a newly developed technique for the characterization of suspended particles, which measurements capture light attenuation due to scattering and absorption of the measured particles, and provide information on the physical and chemical character of the particles. Multiwavelength transmission spectroscopy has many advantages such as easy operation, no reaction reagents, nondamage, rapid measurement, especially, and can obtain multiple parameters of the measured cells. This technique has been proved to be sensitive for the characterization of human blood cells [24, 25], algae cells [26, 27], protozoa cells [28], and bacteria cells [29].

Several common methods for the characterization of bacteria by this spectroscopy analysis have been reported, 
Yet, most of the reported methods require that either the Rayleigh scattering be assumed a priori or that multianglescattering spectrum be detected $[30,31]$.

In this article, we present a new spectroscopy method for the characterization of $E$. coli with multiwavelength transmission spectroscopy. It is demonstrated that quantitative information on the cell size, number, nucleotides, and protein content of $E$. coli can be estimated herein. These characteristic parameters can be used effectively for the rapid identification and detection of $E$. coli in water supplies.

\section{Methodology}

2.1. Mie Theory. According to the Mie theory, the turbidity spectrum of prokaryote was defined with an assumption of monodisperse spherical cell population as

$$
\tau(\lambda)=N_{p} \ell\left(\frac{\pi}{4}\right) Q_{\text {ext }}(m, \lambda, D) D^{2}
$$

where $N_{p}$ is the number of cells, $\ell$ is the path length, $\lambda$ is the wavelength in the medium, $D$ corresponds to the average diameter of the cell, and $Q_{\text {ext }}(m, \lambda, D)$ is the extinction efficiency, which is a function of the cell size, the wavelength, and the refractive index ratio of the cell to the medium.

If the absorption by cells in the medium is negligible, the extinction efficiency is equal to the scattering efficiency $Q_{\text {ext }}(m, \lambda, D)=Q_{\text {sca }}(m, \lambda, D)$.

Assuming that biological cells are approximate to homogeneous spherical particles, the scattering coefficient $Q_{\text {sca }}$ is computed from the rigorous Mie theory as given by [32]:

$$
\begin{aligned}
Q_{\text {sca }} & =\frac{2}{\alpha^{2}} \sum_{n=1}^{\infty}(2 n+1)\left(\left|a_{n}\right|^{2}+\left|b_{n}\right|^{2}\right), \\
a_{n} & =\frac{\psi_{n}^{\prime}(m \alpha) \psi_{n}(\alpha)-m \psi_{n}(m \alpha) \psi_{n}^{\prime}(\alpha)}{\psi_{n}^{\prime}(m \alpha) \xi_{n}(\alpha)-m \psi_{n}(m \alpha) \xi_{n}^{\prime}(\alpha)}, \\
b_{n} & =\frac{m \psi_{n}^{\prime}(m \alpha) \psi_{n}(\alpha)-\psi_{n}(m \alpha) \psi_{n}^{\prime}(\alpha)}{m \psi_{n}^{\prime}(m \alpha) \xi_{n}(\alpha)-\psi_{n}(m \alpha) \xi_{n}^{\prime}(\alpha)},
\end{aligned}
$$

where a dimensionless particle size $a$ is equal to $\pi D / \lambda$ and $m$ is the ratio of refractive index of the cells $n(\lambda)$ to the refractive index of the medium $n_{0}(\lambda)$, where $n_{0}(\lambda)$ is the refractive index of water [33]. Mie coefficients $a_{n}$ and $b_{n}$ are the complex function of $a$ and $m$ [32].

$$
\begin{aligned}
& \psi_{n}(x)=\sqrt{\frac{\pi x}{2}} J_{n+(1 / 2)}(x), \\
& \xi_{n}(x)=\sqrt{\frac{\pi x}{2}} H_{n+(1 / 2)}^{(2)}(x),
\end{aligned}
$$

where $J_{n+(1 / 2)}$ is the semi-integer order Bessel function and $H_{n+(1 / 2)}^{(2)}(x)$ is the second kind Henkel function.

2.2. Beer-Lambert Law. If the scattering effects of the measured cells are negligible, the decreased light intensity is only caused by the absorption of chemical composition of cells. In accordance with the Beer-Lambert law, the absorbance is written as

$$
A=\log \frac{I_{0}}{I_{t}}=\varepsilon\left(\lambda_{0}\right) c \ell,
$$

where $A$ is the measured absorbance, $\varepsilon(\lambda)$ corresponds to a wavelength-dependent absorption coefficient, $c$ is the concentration of chemical composition, and $\ell$ is the sample path length. Clearly, if the absorption coefficient and the path length are known, (4) can be used to estimate the concentration of chemical composition.

\section{Experimental and Materials}

3.1. Bacterial Strain and Sample Preparation. E. coli (CICC number 10389) was obtained from the China Center of Industrial Culture Collection (CICC). The bacterial suspension was made by activating the bacteria, culturing at $37^{\circ} \mathrm{C}$ in beef extract peptone medium ( $\mathrm{pH} 7.0$ ) containing $0.3 \%$ beef extract, $1 \%$ peptone, $0.5 \% \mathrm{NaCl}$, and $2 \%$ agar, expanding propagating in solution culture, centrifuging in the centrifuge (H-1650, Jiangdong Instrument), and washing in sterilized deionized water.

3.2. Spectroscopy Measurements. The multiwavelength transmission spectra of $E$. coli were recorded by a UV/visible spectrophotometer (UV 2550 Shimadzu, Kyoto, Japan) in the region from 230 to $820 \mathrm{~nm}$. The instrument records the spectra which represent the averages of 3 replicate measurements with $1 \mathrm{~nm}$ sampling intervals. To eliminate the effect of inhomogeneity in the suspending medium, the sterilized deionized water was used as reference solution. All measurements were made using a $1 \mathrm{~cm}$ path-length quartz cuvettes at room temperature.

3.3. Plate Count Method. Cell suspensions ( $1 \mathrm{ml}$ ) were diluted with $9 \mathrm{ml}$ sterilized deionized water to obtain serial dilutions $\left(10^{-1}-10^{-9}\right)$ from bacterial suspensions. Each dilution solution $(1 \mathrm{ml})$ drawn by the pipette and nutrient agar medium at $45^{\circ} \mathrm{C}$ was poured into the sterile plate. These plates were incubated at $37^{\circ} \mathrm{C} / 24 \mathrm{~h}$ and $\mathrm{CFU}$ counted [13].

3.4. Cell Size. The cell size was observed by Gram's staining and oil microscopy (Olympus, CX41), E. coli cells were considered as ellipsoids. The following formula was used to calculate the cell volume $(V)$, from the width $(w)$ and the length $(l)$ of the cells: $v=(\pi / 6) \cdot l \cdot \omega^{2}$. Bacterial length and width were calculated by means of the averages of 20 cell length measurements and width measurements, respectively.

\section{Results and Discussion}

4.1. Experimental Results. The multiwavelength transmission spectra of E. coli in the region from 230 to $820 \mathrm{~nm}$ after culture for 16 hours are shown in Figure 1; the abscissa stands for wavelength and the ordinate stands for optical density. The spectra in the wavelength region between 400 and $820 \mathrm{~nm}$ change gently without obvious absorption peaks, which are mainly indicative of the scattering of the cells and its internal structure, and reflect differences in the 


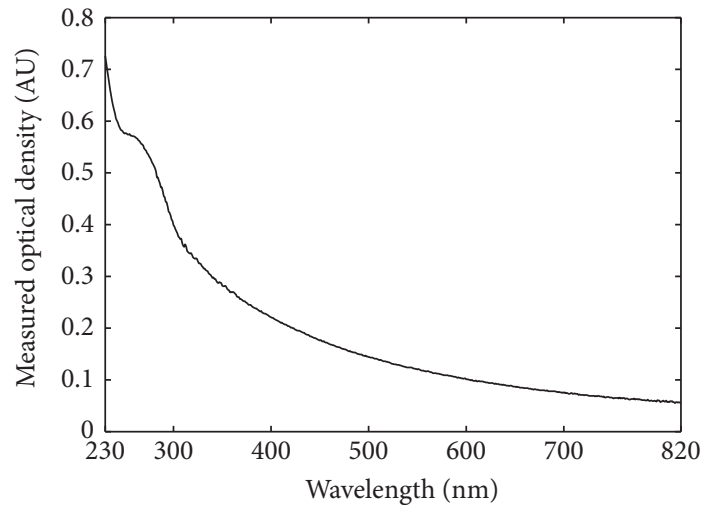

FIgURE 1: Multiwavelength transmission spectra of purified E. coli.

number, size, and internal structure of the cells. The spectra in the region from 230 to $400 \mathrm{~nm}$ appear to be clearly more intense than that of the former, which includes not only the scattering information but also the absorption information of bacteria. Notice in the spectra of $E$. coli the shoulder peak at around $260 \mathrm{~nm}$, this is due to the absorption which is caused by the chemical constituents of the E. coli.

4.2. Spectral Analysis: Scattering Component. The refractive index changes with the presence of mitochondria and plasmids in E. coli. Therefore, the cell is divided into two structural groups: the cell body and the internal structure [34].

The refractive index of the cell body of $E$. coli is given by [35]

$$
n\left(\lambda_{0}\right)=1.3776+\frac{3034.9100}{\lambda_{0}^{2}}
$$

And for the internal structure [31],

$$
n\left(\lambda_{0}\right)=1.5500+\frac{5900}{\lambda_{0}^{2}}
$$

In the region from 230 to $820 \mathrm{~nm}$, the variance of size distribution has little impact on optical density [25]; therefore, if the absorption is negligible, the optical density of scattered spectra (1) can be rewritten:

$$
\begin{aligned}
\tau\left(\lambda_{0}\right)= & N_{p} l\left(\frac{\pi}{4}\right)\left(x Q_{1 \text { sca }}\left(1.3776+\frac{3034.9100}{\lambda_{0}{ }^{2}}, D_{1}\right) D_{1}{ }^{2}\right. \\
& \left.+(1-x) Q_{2 \text { sca }}\left(1.5500+\frac{5900}{\lambda_{0}{ }^{2}}, D_{2}\right) D_{2}{ }^{2}\right),
\end{aligned}
$$

where $N_{p}$ is the bacteria concentration, $\ell$ is the scattering path length, and $Q_{1 s c a}$ and $Q_{2 s c a}$ are the scattering coefficients of the macrostructure and internal structure of bacteria, respectively. $D_{1}$ and $D_{2}$ are the equivalent diameters of the macrostructure and internal structure of bacteria, respectively.

Bacterial concentration is not easily controlled in spectral measurement; in order to exactly calculate the diameters of the macrostructure and internal structure of the bacteria,

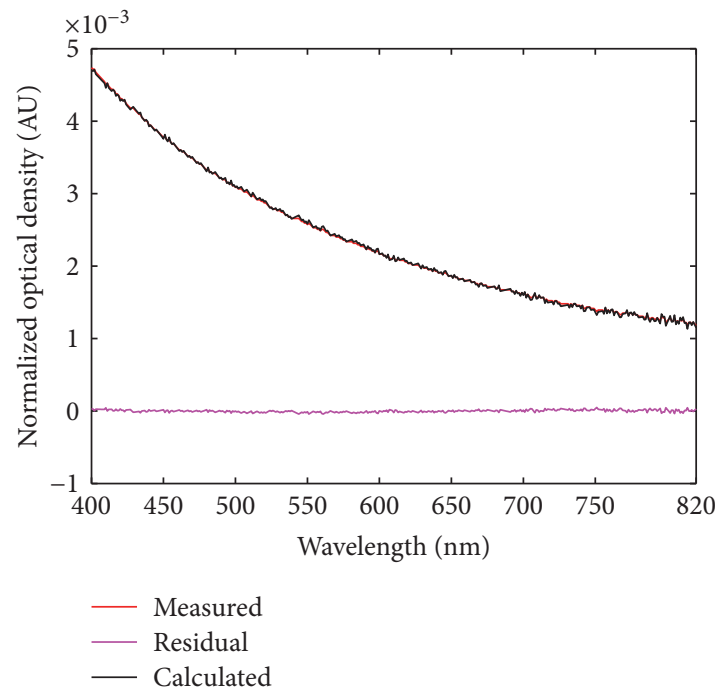

Figure 2: Comparison between measured and calculated normalized optical density spectra of $E$. coli in the wavelength range from 400 to $820 \mathrm{~nm}$, the residuals are included.

the measured spectra are normalized with the total optical density between 230 and $820 \mathrm{~nm}$.

As in the region from 400 to $820 \mathrm{~nm}$ where little to no absorption occurs, these spectra lie mainly in the scattering by cell suspension. Therefore, theoretically, the measured spectra in this region (400-820 nm) of E. coli can be calculated by (7), which is a function of the selected structural parameters of $E$. coli. By a nonlinear least squares optimization algorithm, the normalized measured spectra in the $400-820 \mathrm{~nm}$ wavelength range are fitted by the calculated spectra with (7), and the calculated spectra are iterated until relative changes in the sum of squares are less than $10^{-8}$. The fitting results are shown in Figure 2, clearly indicating that good agreement between the measured and calculated spectra. The average relative error is $0.70 \%$, and the maximum relative error is $2.79 \%$. It is evident that the calculated spectra can represent the scattering features of measured spectra.

From the analysis of the scattered spectra, Table 1 shows the structural parameters of E. coli including cell volume, average diameter, internal structure diameter, and contribution of internal structure, where data from the microscopy method has also been included. It can be seen that average diameter of E. coli is $1.4777 \mu \mathrm{m}$, in order to be compared with the microscopy analysis. Assuming a spherical shape for the bacterial cell, the calculated volume of the average cell is $1.6899 \mu \mathrm{m}^{3}$, which is in a good agreement with the result of microscopy analysis (the relative error is $7.90 \%$ ).

Obviously, when the incident wavelength is fixed, the measured spectrum has linear relationships with single bacterial cell spectra. Therefore, a plot of measured optical density, as a function of a single bacterial optical density calculated from the structural parameters in Table 1 , is shown in Figure 3, where the measured optical density is fitted using the linear equation:

$$
y=a x+b,
$$


TABLE 1: The calculated values by scattered spectra of $E$. coli $(400-820 \mathrm{~nm})$.

\begin{tabular}{|c|c|c|}
\hline E. coli & Calculated values & Microscopy \\
\hline Volume $\left(\mu \mathrm{m}^{3}\right)$ & 1.6899 & 1.5661 \\
\hline Average diameter $D_{1}(\mu \mathrm{m})$ & 1.4777 & $\begin{array}{l}\text { Length: } 3.3266 \\
\text { Width: } 0.9482\end{array}$ \\
\hline $\begin{array}{l}\text { Internal structure } \\
\text { diameter } D_{1}(\mu \mathrm{m})\end{array}$ & 0.0639 & - \\
\hline $\begin{array}{l}\text { Contribution of internal } \\
\text { structure }(\%)\end{array}$ & 28.32 & $30[40]$ \\
\hline
\end{tabular}

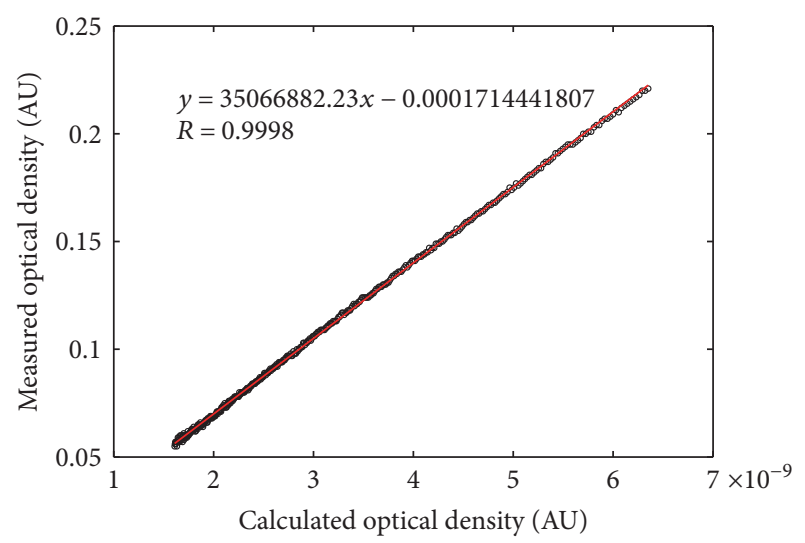

Figure 3: Plot of measured optical density as a function of a single bacterial optical density, the continuous line corresponds to a fitting using (8).

where $a$ and $b$ are the fitting parameters, which results are $a=35066882.23$ and $b=-0.0001714441807$, with a correlation coefficient $=0.9998$, indicating that these data are well fitted by this equation. The bacterial concentration $N_{p}$ is calculated using the formula $a=(\pi / 4) N_{p} l$, where $l=1 \mathrm{~cm}$. Compared with bacterial concentration obtained from plate counting, the relative deviation calculated by $\left(N_{p}-N\right) / N$ is $1.02 \%$, where $N$ is the observations from the plate counting, as given in Table 2.

4.3. Spectral Analysis: Absorption Component. Knowing the structural parameters and bacterial concentration of E. coli, the scattered spectra are computed by (7); the absorption component spectra in the $230-820 \mathrm{~nm}$ wavelength range are computed by subtracting the scattered spectra from the measured transmission spectra for Figure 4. Also, notice that the absorption component has a strong peak in the region from 230 to $300 \mathrm{~nm}$, this is due to the absorption caused by the chemical composition of E. coli. Therefore, the spectral feature of absorption component in the region between 230 and $300 \mathrm{~nm}$ could be used for determination of chemical composition parameter purposes.

E. coli is a typical gram-negative, nonspore, rod-shaped bacterium, whose main chemical components are protein and nucleic acid (approximately 80 percent of the cell's dry weight), its minor constituents, carbohydrate $(8.4 \%)$, lipid $(9.1 \%)$, and coenzyme $(2.5 \%)$ [36, 37]. Chemical
TABLE 2: The calculated values by absorption component of E. coli spectral data $(250-300 \mathrm{~nm})$

\begin{tabular}{lcc}
\hline E. coli & Calculated values & Literature/experiment \\
\hline Nucleic acid (g/cell) & $7.1335 \times 10^{-14}$ & $7.0 \times 10^{-14}$ \\
Protein $(\mathrm{g} /$ cell) & $1.1764 \times 10^{-13}$ & $8.6 \times 10^{-14} \sim 5 \times 10^{-13}$ \\
Concentration $N_{\mathrm{P}}$ & $44649000 / \mathrm{ml}$ & $44200000 / \mathrm{ml}$ \\
\hline
\end{tabular}

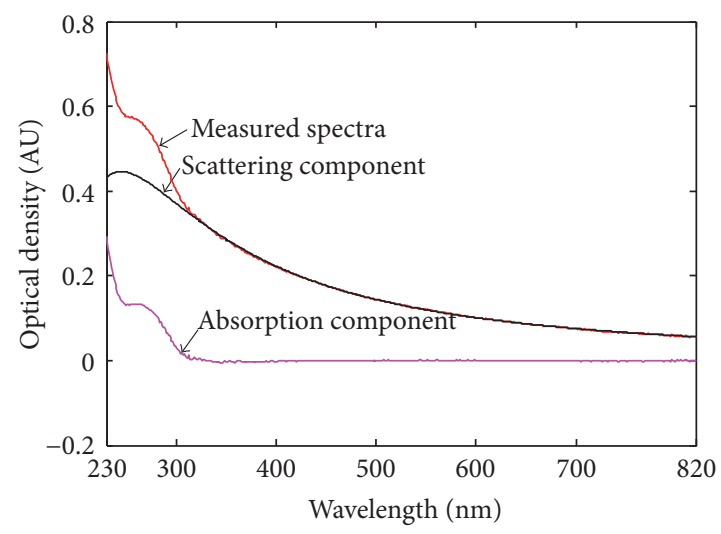

FIgURE 4: The decomposition of $E$. coli spectral data: scattering and absorption components.

composition of microorganisms, such as protein, nucleic acid, and dipicolinic acid, plays a significant role in the absorption of ultraviolet light [38]. Figure 5 shows a comparison of the absorption coefficient of nucleic acid, chromophoric amino acids, and dipicolinic acid weighted by their typical concentration versus wavelength.

In order to accurately calculate the chemical composition content of bacteria, the proportion of nucleic acid and protein are judged. Figure 4 shows the optical density of the absorption component spectra. Knowing $\mathrm{OD}_{280}=0.1065$, $\mathrm{OD}_{260}=0.1338$, and $\mathrm{OD}_{280} / \mathrm{OD}_{260}=0.7960$, this proportion between 0.5 and 1.8 clearly indicates that the chemical compositions of nucleic acid and protein exist in bacteria.

There are 20 kinds of amino acids that make up protein in organisms, most of which have no absorption in the 230-310 nm wavelength range; only the aromatic amino acids (tyrosine, phenylalanine, and tryptophan) have absorption in the 250-300 $\mathrm{nm}$ region, and its maximum absorption wavelength is at $280 \mathrm{~nm}$ [20]. The ribose and phosphoric acid in the nucleic acids have no absorption in the UV region; however, purine and pyrimidine bases with conjugated double bond systems have strong absorption in the 250-280 $\mathrm{nm}$ wavelength range [39]. Therefore, the spectra in the wavelength region between 250 and $300 \mathrm{~nm}$, which is the strongest absorption band of nucleic acid and protein, could be analyzed for determination of nucleic acid and protein concentration.

According to the Beer-Lambert Law, the optical density at the fixed wavelength is proportional to the absorption coefficient of chemical compositions of bacteria. But the components of E. coli are complex, besides nucleic acid and protein have absorption for light, other components have 


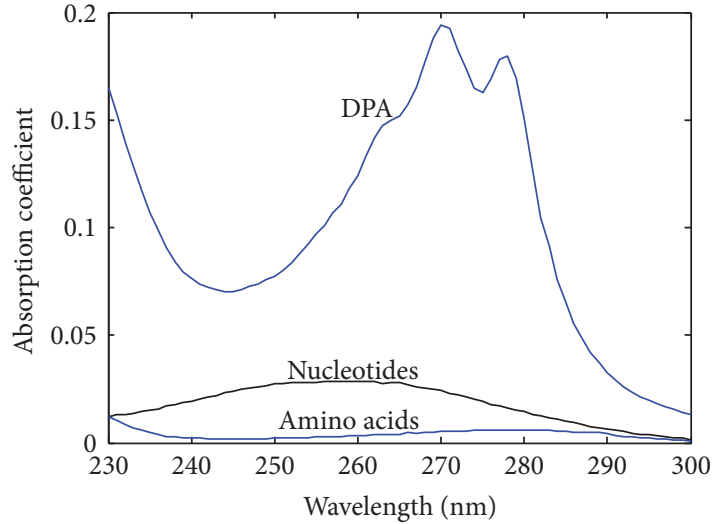

FIGURE 5: Comparison of the absorption coefficient of total nucleic acid, chromophoric amino acids, and dipicolinic acid weighted by their typical concentration in microorganism [38].

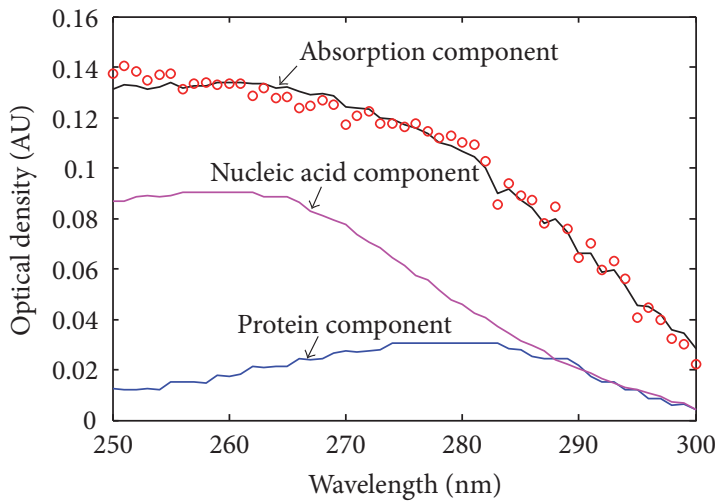

FIgURE 6: Quantitative analysis of E. coli absorption component: nucleic acid and protein components.

some influence on optical density. The absorbance component optical density of $E$. coli can be expressed as

$$
\mathrm{OD}(\lambda)=c_{1} \varepsilon_{1}(\lambda)+c_{2} \varepsilon_{2}(\lambda)+c_{0}
$$

where $\varepsilon_{1}(\lambda)$ and $\varepsilon_{2}(\lambda)$ are the absorption coefficients of nucleic acid and protein, respectively. $c_{1}$ and $c_{2}$ are the concentration of nucleic acid and protein, respectively. $c_{0}$ is a constant, in which its optical density generated other components.

The absorption spectra in the $250-300 \mathrm{~nm}$ wavelength range are calculated, following (9). Clearly, the multiple linear regression analysis method is used for the determination of nucleic acid and protein content. As shown in Figure 6, the absorbance component optical density can be written as

$$
y=3.1850 x_{1}+5.2525 x_{2}+0.0261,
$$

where nucleic acid content $c_{1}=3.1850$ and protein content $c_{2}=5.2525$, with a correlation coefficient of 0.98786 indicating that these data are well fitted by (10).

The protein and nucleic acid content of single bacterium are calculated by nucleic acid content $c_{1}$, protein content $c_{2}$, and cell number $N_{p}$, as given in Table 2 .

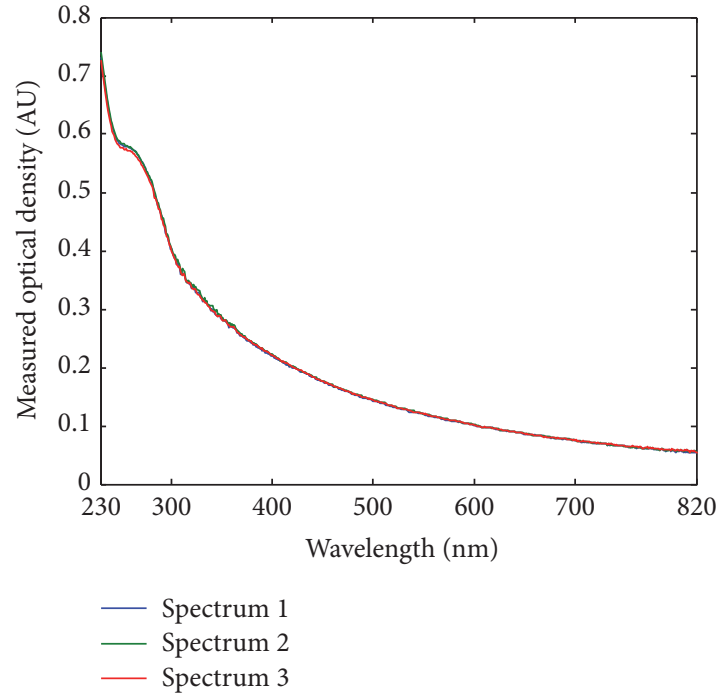

FIgURE 7: Three measured multiwavelength transmission spectra $(230-820 \mathrm{~nm})$ of purified E. coli.

TABLE 3: The calculated values from the three multiwavelength transmission spectra.

\begin{tabular}{lccccc}
\hline Spectrum & $\begin{array}{c}D_{1} \\
(\mu \mathrm{m})\end{array}$ & $\begin{array}{c}\text { Volume } \\
\left(\mu \mathrm{m}^{3}\right)\end{array}$ & $\begin{array}{c}N_{\mathrm{P}}\left(\times 10^{7}\right. \\
\text { cells } / \mathrm{ml})\end{array}$ & $\begin{array}{c}\text { Nucleic } \\
\text { acid } \\
\left(\times 10^{-14}\right. \\
\mathrm{g} / \text { cell })\end{array}$ & $\begin{array}{c}\text { Protein } \\
\left(\times 10^{-13}\right. \\
\mathrm{g} / \text { cell })\end{array}$ \\
\hline 1 & 1.4368 & 1.5531 & 4.5143 & 7.0514 & 1.1805 \\
2 & 1.4399 & 1.5631 & 4.4892 & 7.4581 & 1.2742 \\
3 & 1.4777 & 1.6899 & 4.4649 & 7.1335 & 1.1764 \\
RSD & 0.015689 & 0.047601 & 0.005502 & 0.029835 & 0.045705 \\
\hline
\end{tabular}

As indicated in Table 2, the amount of nucleic acid estimate is $7.1335 \times 10^{-14} \mathrm{~g} / \mathrm{cell}$, which is almost the same as the value reported in the literature $\left(7.0 \times 10^{-14},[40]\right)$. In addition, the protein content estimate is certainly within the range of values reported in the literature [41], which were obtained with entirely different approach. It means that the amounts of nucleic acid and protein of $E$. coli could be obtained with the interpretation of the absorption component spectra.

In order to verify the repeatability of the method, for the same E. coli cell suspension, the three measured optical density spectra $(230-820 \mathrm{~nm})$ are collected (Figure 7); according to the proposed analysis, several parameters are calculated in Table 3, and their relative standard deviation (RSD) is less than $5 \%$. The low RSD values provide evidence that the method has better precision.

\section{Conclusions}

We propose a new approach to obtain average size, number, and chemical composition of $E$. coli cells from multiwavelength transmission spectra. According to the analysis of the scattering spectra in the wavelength range from 400 to 
$820 \mathrm{~nm}$, the structural parameters of $E$. coli can be obtained; compared with the microscopy, the relative error of cell volume is $7.90 \%$. The cell number was obtained by using linear fitting; compared to plate counting, the relative error of cell number is $1.02 \%$. The absorbance components of the spectra in the wavelength which range from 250 to $300 \mathrm{~nm}$ are further analyzed based on the Beer-Lambert Law; the compositional information on nucleic acid and protein content can be obtained, which agrees with literature values reported for E. coli. It is evident that multiwavelength transmission spectroscopy has the potential to obtain accurate information about the number and the structural and compositional characteristics of bacterial cells, which provides a simple, rapid, and accurate means for the detection and warning of bacteria in the water.

\section{Conflicts of Interest}

The authors declare that there is no conflict of interests regarding the publication of this paper.

\section{Acknowledgments}

This work was supported by the Natural Science Foundation of Anhui Province (nos. 1508085JGD02 and 1608085QF137), the Science and Technology Key Project of Anhui Province (no. 15CZZ04125), and the National Natural Science Foundation of China (no. 61378041 and no. 61705237).

\section{References}

[1] Z. H. Liao, Y. H. Luo, Z. L. Jiang, and J. Y. Xiu, "Resonance scattering spectroscopic study of coli bacillus," Analysis and Testing Technology and Instruments, vol. 9, no. 2, pp. 65-69, 2003.

[2] P. Geng, Research on the application of electro-analytical methods of the rapid detection of E. coli, Master Thesis, East China Normal University, 2008.

[3] P. Shen and X. D. Chen, Microbiology, Advanced Education Press, Beijing, 8th edition, 2016.

[4] R. R. Hu, Z. Z. Yin, Y. B. Zeng et al., "A novel biosensor for Escherichia coli O157:H7 based on fluorescein-releasable biolabels," Biosensors and Bioelectronics, vol. 78, pp. 31-36, 2016.

[5] A. M. Loske, E. M. Tello, S. Vargas, and R. Rodriguez, "Escherichia coli viability determination using dynamic light scattering: a comparison with standard methods," Archives of Microbiology, vol. 196, no. 8, pp. 557-563, 2014.

[6] R. Parveen, S. Saha, S. Shamshuzzaman, A. L. Rashid, A. Chowdhury, and N. Muazzam, "Detection of uropathogens by using chromogenic media (Hicrome UTI agar), CLED agar and other conventional media," Faridpur Medical College Journal, vol. 6, no. 1, pp. 46-50, 2011.

[7] Y. Moreno, P. Piqueres, J. L. Alonso, A. Jiménez, A. González, and M. A. Ferrús, "Survival and viability of Helicobacter pylori after inoculation into chlorinated drinking water," Water Research, vol. 41, no. 15, pp. 3490-3496, 2007.

[8] M. Barreiros dos Santos, C. Sporer, N. Sanvicens et al., "Detection of pathogenic bacteria by electrochemical impedance spectroscopy: influence of the immobilization strategies on the sensor performance," Procedia Chemistry, vol. 1, no. 1, pp. 1291-1294, 2009.

[9] K. Chand, S. K. Biswas, B. Sing, A. De, and B. Mondal, "A sandwich ELISA for the detection of bluetongue virus in cell culture using antiserum against the recombinant VP7 protein," Veterinaria Italiana, vol. 45, no. 3, pp. 443-448, 2009.

[10] N. Esiobu, "Use of peptide nucleic acid probes for rapid detection and enumeration of viable bacteria in recreational waters and beach sand," Methods in Molecular Biology, vol. 345, pp. 131-140, 2006.

[11] H. Y. Tsen, C. K. Lin, and W. R. Chi, "Development and use of 16S rRNA gene targeted PCR primers for the identification of Escherichia coli cells in water," Journal of Applied Microbiology, vol. 85, no. 3, pp. 554-560, 1998.

[12] M. Mölsä, K. A. Koskela, E. Rönkkö, N. Ikonen, T. Ziegler, and S. Nikkari, "Detection of influenza A viruses with a portable real-time PCR instrument," Journal of Virological Methods, vol. 181, no. 2, pp. 188-191, 2012.

[13] P. Poltronieri, F. Cimaglia, E. de Lorenzis, M. Chiesa, V. Mezzolla, and I. Reca, "Protein chips for detection of Salmonella spp. from enrichment culture," Sensors, vol. 16, no. 4, p. 574, 2016.

[14] M. Sohn, D. S. Himmelsbach, F. E. Barton 2nd, and P. J. Fedorka-Cray, "Fluorescence spectroscopy for rapid detection and classification of bacterial pathogens," Applied Spectroscopy, vol. 63, no. 11, pp. 1251-1255, 2009.

[15] I. Altamore, L. Lanzano, and E. Gratton, "Dual channel detection of ultra low concentration of bacteria in real time by scanning fluorescence correlation spectroscopy," $\mathrm{Mea}$ surement Science and Technology, vol. 24, no. 6, article 065702, 2013.

[16] H. E. Giana, L. Silveira Jr, R. A. Zângaro, and M. T. T. Pacheco, "Rapid identification of bacterial species by fluorescence spectroscopy and classification through principal components analysis," Journal of Fluorescence, vol. 13, no. 6, pp. 489-493, 2003.

[17] V. Erukhimovitch, M. Huleihil, and M. Huleihel, "Identification of contaminated cells with viruses, bacteria, or fungi by Fourier transform infrared microspectroscopy," Journal of Spectroscopy, vol. 2013, Article ID 317458, 6 pages, 2013.

[18] J. Wang, K. H. Kim, S. Kim, Y. S. Kim, Q. X. Li, and S. Jun, "Simple quantitative analysis of Escherichia coli K-12 internalized in baby spinach using Fourier transform infrared spectroscopy," International Journal of Food Microbiology, vol. 144, no. 1, pp. 145-151, 2010.

[19] M. Wenning, F. Breitenwieser, R. Konrad, I. Huber, U. Busch, and S. Scherer, "Identification and differentiation of foodrelated bacteria: a comparison of FTIR spectroscopy and MALDI-TOF mass spectrometry," Journal of Microbiological Methods, vol. 103, pp. 44-52, 2014.

[20] J. De Gelder, K. De Gussem, P. Vandenabeele, and L. Moens, "Reference database of Raman spectra of biological molecules," Journal of Raman Spectroscopy, vol. 38, no. 9, pp. 1133-1147, 2007.

[21] I. H. Cho, P. Bhandari, P. Patel, and J. Irudayaraj, "Membrane filter-assisted surface enhanced Raman spectroscopy for the rapid detection of $E$. coli O157:H7 in ground beef," Biosensors and Bioelectronics, vol. 64, pp. 171-176, 2015.

[22] A. Sengupta, M. Mujacic, and E. J. Davis, "Detection of bacteria by surface-enhanced Raman spectroscopy," Analytical and Bioanalytical Chemistry, vol. 386, no. 5, pp. 1379-1386, 2006. 
[23] L. Yuan, J. H. Fang, Y. L. Jin, C. Wang, and T. Xu, "A biomedical surface enhanced Raman scattering substrate: functionalized three-dimensional porous membrane decorated with silver nanoparticles," Journal of Spectroscopy, vol. 2015, Article ID 561919, 5 pages, 2015.

[24] Y. Mattley, G. Leparc, R. Potter, and L. García-Rubio, "Light scattering and absorption model for the quantitative interpretation of human platelet spectral data," Photochemistry and Photobiology, vol. 71, no. 5, pp. 610-619, 2000.

[25] Y. D. Mattley and L. H. Garcia-Rubio, "Multiwavelength spectroscopy for the detection, identification and quantification of cells," Proceedings Volume 4206, Photonic Detection and Intervention Technologies for Safe Food, 2001, pp. 45-51, Environmental and Industrial Sensing, Boston, MA, USA, 2001.

[26] A. H. Spear, K. Daly, D. Huffman, and L. Garcia-Rubio, "Progress in developing a new detection method for the harmful algal bloom species, Karenia brevis, through multiwavelength spectroscopy," Harmful Algae, vol. 8, no. 2, pp. 189-195, 2009.

[27] P. A. Staehr and J. J. Cullen, "Detection of Karenia mikimotoi by spectral absorption signatures," Journal of Plankton Research, vol. 25, no. 10, pp. 1237-1249, 2003.

[28] Y. M. Serebrennikova, J. Patel, and L. H. Garcia-Rubio, "Interpretation of the ultraviolet-visible spectra of malaria parasite Plasmodium falciparum," Applied Optics, vol. 49, no. 2, pp. 180-188, 2010.

[29] M. R. Callahan, R. Robertson, J. B. Rose, and L. H. Garcia Rubio, "Use of multiwavelength transmission spectroscopy for the characterization of Cryptosporidium parvum oocysts: quantitative interpretation," Environmental Science \& Technology, vol. 37, no. 22, pp. 5254-5261, 2003.

[30] A. Katz, A. Alimova, M. Xu et al., "Bacteria size determination by elastic light scattering," IEEE Journal of Selected Topics in Quantum Electronics, vol. 9, no. 2, pp. 277-287, 2003.

[31] J. R. Mourant, M. Campolat, and C. Brocke, "Light scattering from cells: the contribution of the nucleus and the effects of proliferative status," Journal of Biomedical Optics, vol. 5, no. 2, pp. 131-137, 2000.

[32] C. F. Bohren and D. R. Huffman, Absorption and Scattering of Sight by Small Particles, John Wiley \& Sons, New York, 1983.

[33] T. J. Straub and U. Grigull, "Refractive index of water and its dependence on wavelength, temperature, and density," Journal of Physical and Chemical Reference Data, vol. 14, no. 4, pp. 933-945, 1985.

[34] J. Y. Wang, N. J. Zhao, and J. B. Duan, "Rapid quantitative detection of bacterial in water based on multi-wavelength scattering spectra," Spectroscopy and Spectral Analysis, vol. 37, no. 2, pp. 333-337, 2017.

[35] C. E. Alupoaei, J. A. Olivares, and L. H. García-Rubio, "Quantitative spectroscopy analysis of prokaryotic cells: vegetative cells and spores," Biosensors and Bioelectronics, vol. 19, no. 8, pp. 893-903, 2004.

[36] G. Churchward, H. Bremer, and R. Young, "Macromolecular composition of bacteria," Journal of Theoretical Biology, vol. 94, no. 3, pp. 651-670, 1982.

[37] S. Cooper, Bacterial Growth and Division, Academic Press, San Diego, 1991.

[38] C. E. Alupoaei and L. H. García-Rubio, "An interpretation model for the UV-VIS spectra of microorganisms," Chemical Engineering Communications, vol. 192, no. 2, pp. 198-218, 2005.
[39] Y. J. Guo, Spectrophotometric Technique and Its Application in Biochemistry, Science Press, Beijing, 1987.

[40] L. H. Garcia-Rubio, C. E. Alupoaei, J. Olivares et al., "A new spectroscopy method for in-situ rapid detection and classification of microorganisms," Proceeding of SPIE, vol. 5585, pp. 88-97, 2004.

[41] J. A. Valkenburg and C. L. Woldringh, "Phase separation between nucleoid and cytoplasm in Escherichia coli as defined by immersive refractometry," Journal of Bacteriology, vol. 160, no. 3, pp. 1151-1157, 1984. 

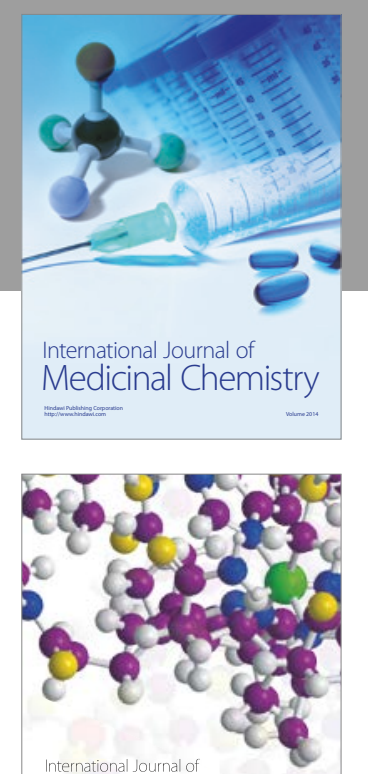

Carbohydrate Chemistry

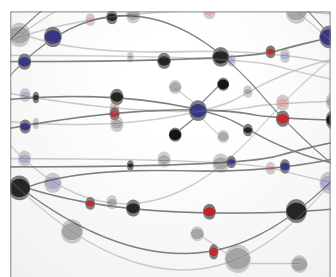

The Scientific World Journal
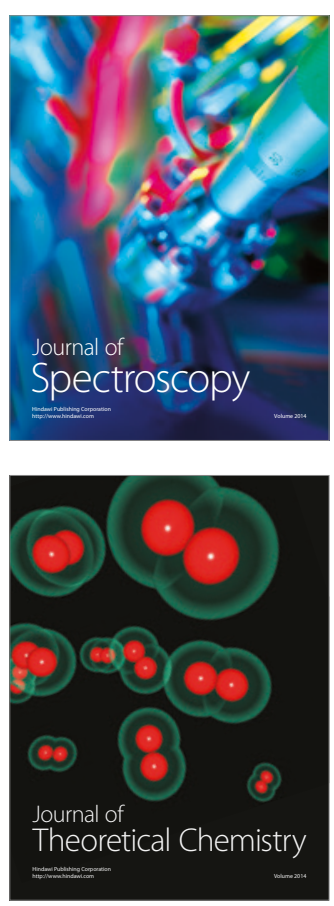
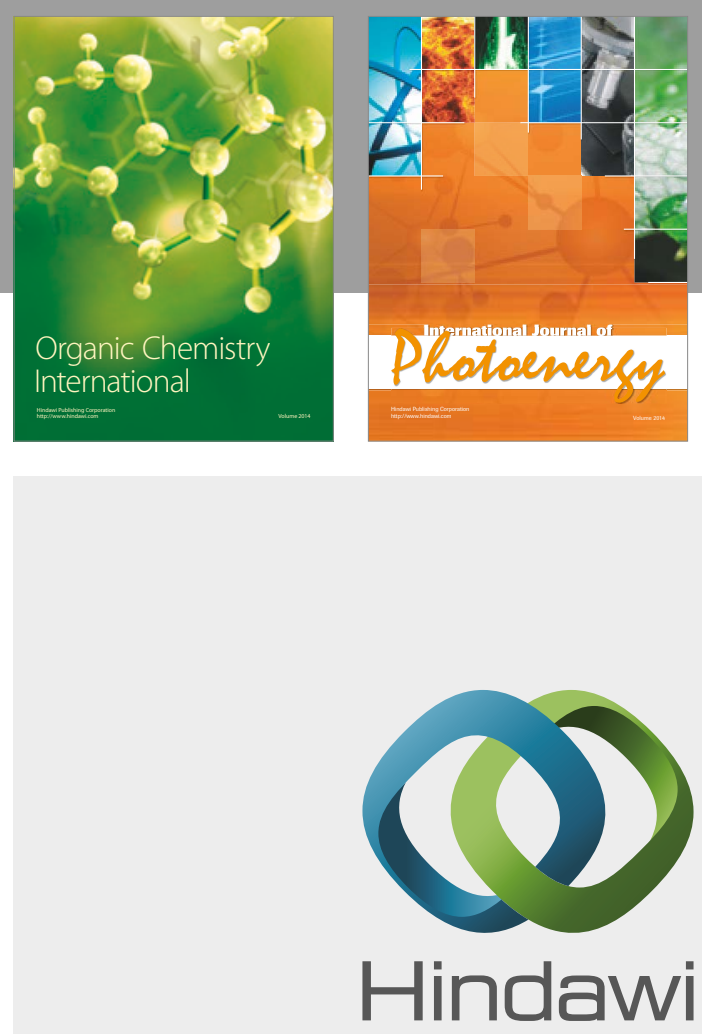

Submit your manuscripts at

https://www.hindawi.com

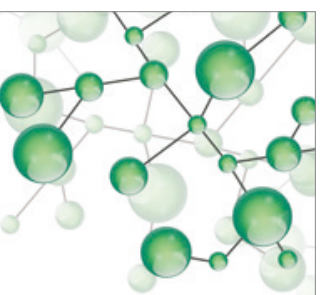

International Journal of

Inorganic Chemistry

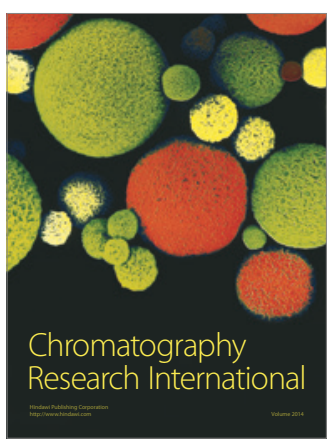

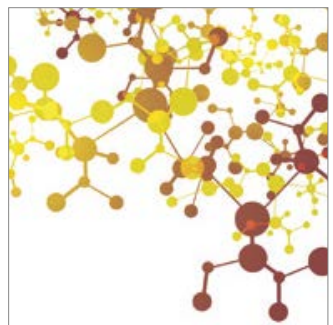

Applied Chemistry
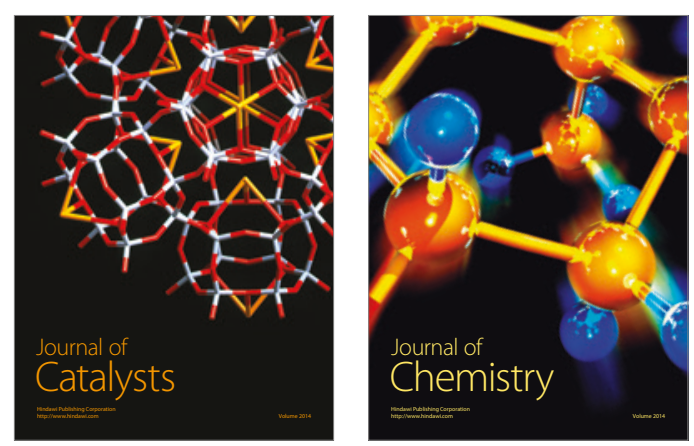
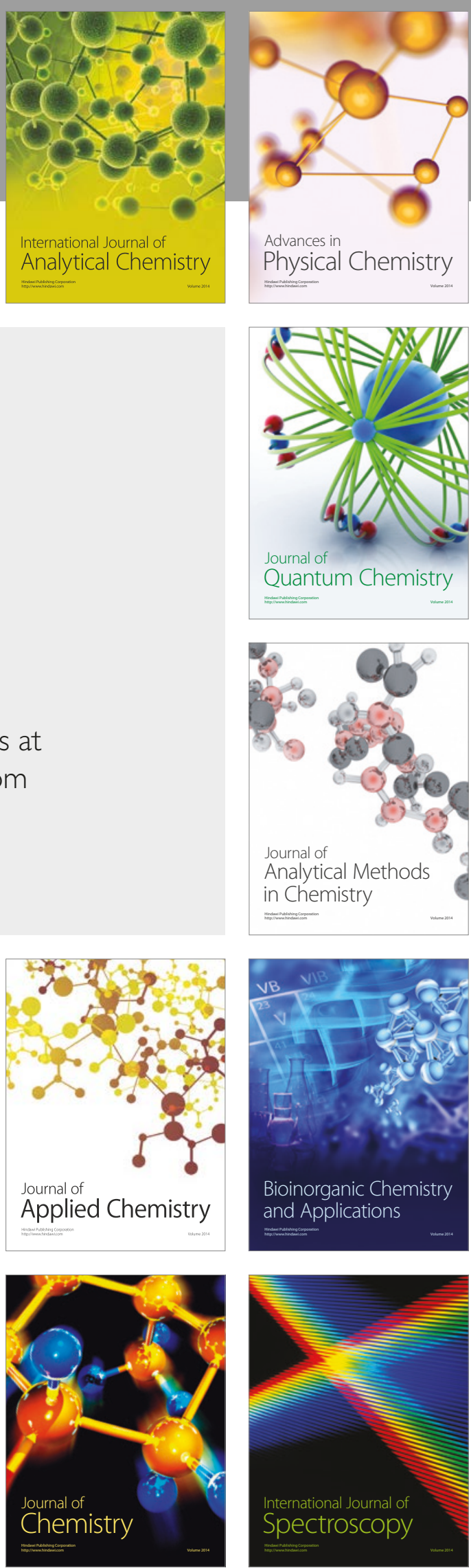